Original Article

\title{
Dry Eye Disease and Pterygium
}

Munir Baig, Rabeeya Munir

Pak J Ophthalmol 2019, Vol. 35, No. 3

See end of article for authors affiliations

Correspondence to:

Munir Baig

Department of Ophthalmology,

Azad Jammu Kashmir Medical College, Muzaffarabad.

Email:

drmuniramjad@gmail.com
Purpose: To find the changes in tear film and ocular surface in patients with pterygium.

Study Design: A descriptive cross sectional study.

Place and Duration of Study: Federal Government Services Hospital Islamabad during June 2013 to December 2014.

Material and Methods: Dry eye questionnaire (DEQ-6) was administered by a trained researcher and DE tests were performed in all 256 willing subjects (136 with pterygium +120 control) age $30-76$ years, by a single surgeon under same physical conditions after taking the consent and approval from Hospital Ethical committee. Diagnosis was made on presence of both symptoms and tear film parameters. Statistical analysis by simple percentages.

Results: Dry eyes (DE) were found in $73(53.7 \%)$ of the pterygium cases and 28 $(23.5 \%)$ of the normal patients. In this study, $55(40.5 \%)$ patients were symptomatic, defined as reporting 1 or more DE symptoms often or all the time. There were $53(39 \%)$ patients that showed corneal fluorescein staining (CFS) and $69(51 \%)$ showed plugging/mucous threads in both groups. Of 136 eyes with pterygium there were $91(67 \%)$ males and $45(33 \%)$ females. Out of these 50 $(36.7 \%)$ patients showed normal tear film and $86(63.2 \%)$ showed deranged functions. Moreover, among the 120 control eyes there were $73(61 \%)$ males and $47(39 \%)$ ] females. Out of these $86(72.3 \%)$ patients were normal and 34 $(27.7 \%)$ had abnormal functions. These values were reduced indicating altered tear film in these patients.

Conclusion: Pterygium disturbs tear functions causing dry eye like symptoms.

Key Words: Dry eye, pterygium, tear film instability, ocular surface.
$\mathrm{P}$ terygium means a wing in Greek and it was first mentioned by Hippocrates. It is a fleshy, pink growth on the conjunctiva also called Surfer's eye. Both pterygium and pinguecula are abnormal growths on ocular surface . $^{1}$

Pterygium has a worldwide distribution but it is common after exposure to ultraviolet radiations in warm and dry weather ${ }^{2}$. Sailors, skiers and sports people have a high incidence of pterygia due to reflected UV lights. Pterygium is also more common in New Zealand ${ }^{3}$ in Ozone layer depletion areas.

Wolff in 1946, emphasized that meibomian glands are the proper glands of the cornea which have moved out of the way in the benefit of vision ${ }^{4}$. Smooth pre- corneal tear film formed after blinking protects the ocular surface to maintain quality of vision ${ }^{5}$.

The knowledge about Dry Eye diseases has improved during last decade. Dry eye is tear film disorder damaging interpalpebral ocular surface and causing unstable tear film ${ }^{6}$. Dry eye is also defined as a disturbance of lacrimal functional unit which consists of lacrimal glands, ocular surface including eyelids, meibomian glands, conjunctiva, cornea, goblet cells, and ocular nerves ${ }^{7}$.

Dry eye is a common disease, affecting about 5$30 \%$ of subjects aged 50 years and older (DEWS 2007) ${ }^{6}$. The Beaver Dam population based study reported incidence of $14 \%$ in adults over $48-91$ years ${ }^{8}$. In 
Australia it is about $7 \%$ in elderly people 9 . In Indonesia it is $27.5 \%$ with more prevalence in older subjects, with pterygium and smokers ${ }^{10}$.

The purpose of this study was to find out the relationship between tear film changes and pterygium.

\section{MATERIAL \& METHODS}

There were 136 patients of 30-76 years attending the eye OPD of Federal Government Services Hospital Islamabad from June 2013 to December 2014 having nasal pterygium and 120 normal volunteers of same age, gender and geographical distribution from refraction clinic who were selected and evaluated after taking their consent. Patients with any surgery, any systemic disease, lacrimal system disease, contact lens or drops use and refractive errors were excluded from the study.

1. Do your eyes ever feel dry?

2. Do you ever feel a gritty or sandy sensation in your eye?

3. Do your eyes ever have a burning sensation?

4. Are your eyes ever red?

5. Do you notice much crusting on your lashes?

6. Do your eyes ever get stuck shut in the morning?

Fig. 1: DEQ-6 Questionnaire.

A 6 item standardized dry eye questionnaire (DEQ-6) (figure 1) was administered and scored by a trained researcher. Tear film breakup time (TBUT), Schirmer's test (ST), corneal fluorescein staining (CFS) for presence of conjunctival injection, punctate epithelial erosions (PEE) and meibomian gland dysfunction (MGD) were assessed by a single surgeon under the same physical conditions. The patients and controls were divided into two groups; group1 in whom both fluorescein break up time and Schirmer's tests were normal and group11 in whom either or both tests were abnormal. The eye with the larger pterygium was evaluated amongst bilateral pterygia. The diagnosis was made on the presence of three out of five parameters. All Data was entered into SPSS version 17 and analyzed for frequencies/percentages.

\section{RESULTS}

Of 256 subjects, age $30-76$ years, $64.8 \%$ were urban, $69.9 \%$ were educated government servants, $22 \%$ were smokers and 29.6\%were laborers. There were 19 (14.1\%) subjects who showed pterygium in both eyes while $117(85.9 \%)$ had pterygium in one eye (Table 1$)$.

Table 1: Baseline characters in cases and control.

\begin{tabular}{|c|c|c|c|}
\hline \multicolumn{2}{|c|}{ Pterygium Subjects $\mathbf{n}=\mathbf{1 3 6}$} & \multicolumn{2}{|c|}{ Normal Eyes $n=120$} \\
\hline Male & $91(67 \%)$ & Male & $71(59 \%)$ \\
\hline Female & $45(33 \%)$ & Female & $49(41 \%)$ \\
\hline Dry eye & $73(53.6 \%)$ & & $27(23 \%)$ \\
\hline Irritation & $91(67 \%)$ & Redness & $39(33 \%)$ \\
\hline Urban & $92(67.4 \%)$ & & $74(32.6 \%)$ \\
\hline \multicolumn{4}{|c|}{ Average pterygium width $5.5 \mathrm{~mm}$} \\
\hline Smokers & $33(24.2 \%)$ & & $22(18 \%)$ \\
\hline Right/Left Eyes & $58 / 78$ & ----- & \\
\hline
\end{tabular}

Of 136 eyes with pterygium 50 (37.5\%) showed normal tear film and $86(62.5 \%)$ showed derranged functions whereas among 120 control eyes 86 (72.3\%) were normal and $34(27.7 \%)$ had abnormal tear functions. These values were reduced indicating tear film instability in these patients.

Burning was the most common symptom reported among 91 (67\%) patients in the case group. Both genders during the fourth decade had more numbers of pterygia. Moreover indoor workers were affected more in both groups (Table 2).

Table 2: Age and gender wise distribution of cases and controls.

\begin{tabular}{|lllcc|}
\hline \multicolumn{2}{|c|}{ Age group } & \multicolumn{2}{c|}{ Eyes with pterygium $=\mathbf{1 3 6}$} & \multicolumn{2}{c|}{ Normal $\mathbf{~}=\mathbf{1 2 0}$} \\
\hline In years & Male & Female & Male & Female \\
$30-39$ & 12 & 6 & 14 & 8 \\
$40-49$ & 29 & 15 & 24 & 16 \\
$50-59$ & 25 & 13 & 22 & 15 \\
$60-69$ & 19 & 11 & 9 & 5 \\
$70-76$ & 6 & - & 2 & 5 \\
Total & $91(67 \%)$ & $45(33 \%)$ & $71(59 \%)$ & $49(41 \%)$ \\
\hline
\end{tabular}

At limbus the average pterygium width was 5.5 $\mathrm{mm}$ and average corneal involvement was $4.0 \mathrm{~mm}$. Dry eye tests showed low tear film breakup time TBUT ( $<$ or $=10$ seconds) and low Schirmer test ST (<or $=5 \mathrm{~mm} / 5 \mathrm{~min}$.) in $86(63 \%)$ and $46(34 \%)$ of subjects respectively (Table 3 ) where the mean TBUT and ST values were 8.56 seconds and $12.19 \mathrm{~mm}$ respectively and in control group it was 22.25 seconds and $18.50 \mathrm{~mm} / 5 \mathrm{~min}$. There were $53(39 \%)$ patients who showed corneal fluorescein staining CFS and 69 
(51\%) showed plugging/mucous threads in both groups. Dry eye tests in cases and controls are shown in Table 4.

Table 3: TBUT percentages.

\begin{tabular}{|lllllll|}
\hline TBUT & \multicolumn{2}{l}{$\mathbf{1 0}$ secs } & $\mathbf{1 0 - 1 5} \mathbf{~ s e c}$ & \multicolumn{3}{c|}{$>\mathbf{1 5 s e c}$} \\
\hline & \multicolumn{3}{l}{ Abnormal } & \multicolumn{2}{c|}{ Borderline } & \multicolumn{2}{c|}{ Normal } \\
& $\mathrm{N}=$ & $(\%)$ & $(\mathrm{n}=$ & $(\%)$ & $(\mathrm{n}=$ & $(\%)$ \\
Cases & 86 & $63 \%$ & 30 & $22 \%$ & 20 & $14.7 \%$ \\
Control & 16 & $13.3 \%$ & 13 & $11.1 \%$ & 91 & $75.5 \%$ \\
\hline
\end{tabular}

Table 4: Dry eye tests in cases and controls.

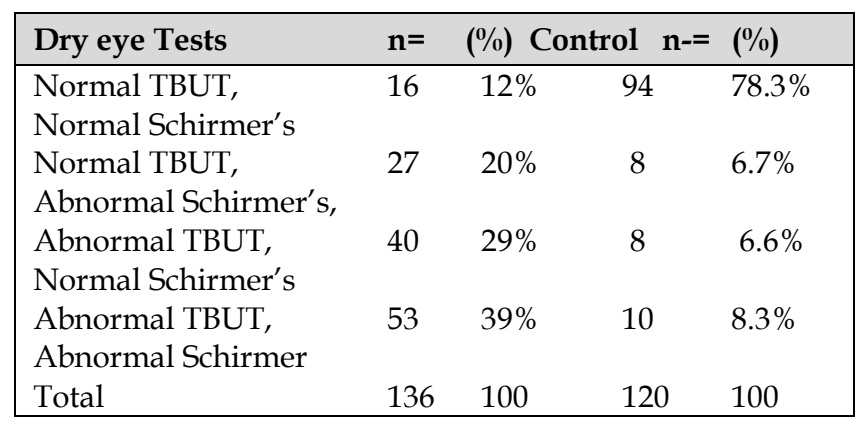

\section{DISCUSSION}

The pathogenesis of pterygium is not understood completely. In equatorial regions ultraviolet radiations cause pterygium formation specifically UV-B radiations. Studies show that p53 tumor suppressor gene undergoes mutations leading to abnormal limbal epithelium proliferation. The possible risk factors are age, hereditary factors, chronic inflammation, smoking, lower education, high refractive errors, sunlight, heat and micro trauma ${ }^{11}$.

It is common in the general population and progresses slowly but has little effect on vision. In our study most of the cases of pterygium were found in the fourth decade (40-49 years). It is similar to another study ${ }^{12}$. In advanced age excessive exposure to sun light causes the formation of pterygium. But, recent studies denied any relation of age with the pterygium incidence ${ }^{13}$.

In our study pterygium was seen more in patients with indoor activities contrary to the study of Viso et al, $(2011)^{14}$. In Islamabad the indoor laborers (53\%) suffered more than outdoor labourers $(47 \%)$ with pterygium because in Islamabad they used to work 4-5 hours/day in the kitchen. Similarly, new studies denied any relationship between nature of work and pterygium ${ }^{2}$.
The tear film breakup time using fluorescein break is used to measure the tear film quality ${ }^{15}$. Our study indicated abnormal TBUT test in $62.2 \%$ of pterygium eyes and in $27.7 \%$ of eyes without pterygium. Another study reported reduced TBUT test in 30.3\% of pterygium group and $21.9 \%$ eyes without that ${ }^{16}$. Another study reported TBUT instability in $39.7 \%$ eyes with pterygium and in $23 \%$ eyes without it ${ }^{17}$. Bekibele et al 18 mentioned lower TBUT values in pterygium patients than normal eyes similar to our study.

Our results revealed reduced ST values in 34\% of patients of pterygium group similar to the study of Roka et al, 2013 ${ }^{19}$. Conversely, the study of Kampitak and Leelawongtawun showed that the ST results did not change in pterygium patients ${ }^{20}$.

Tear functions improved as TBUT and Schirmer test were prolonged. $\mathrm{Li}$ et al found improvement in tear function in patients after pterygium excision ${ }^{21}$. However, $\mathrm{Li}$ and colleagues noticed that there is no difference in Schirmer test values after pterygium operations. Li et al. reported both tear quality and quantity decrease in pterygium group with a decrease in goblet cell population. Turkyilmaz et al.22 found that the mean goblet cell density was increased 1 month after excision. Moreover, Ye et al reported that both tear film break-up time and Schirmer test were different in study and control groups similar to our study ${ }^{23}$.

In the literature no cases of pterygium were found in children below the age of 5 years. This study revealed that $67 \%$ males were more affected than $33 \%$ females. One Study ${ }^{2}$ noticed no gender dependence. Another study from rural Dali in China noticed an increased pterygium formation in females than men ${ }^{24}$. The lifestyle of labor between the genders may be the reason. A study by Peng et al in Tibet reported that women were at a higher risk than men related with their lifestyle. In Tibet, women were more often involved in outdoor activities and jobs ${ }^{25}$.

It has been found that excessive use of drops containing preservatives can destroy goblet cells and the ocular surface resulting in $\mathrm{DE}^{16}$. A pterygium induces astigmatism if larger than $3 \mathrm{~mm}$. More than $3.5 \mathrm{~mm}$ lesions can result in more than $1 \mathrm{D}$ of astigmatism causing blurring of vision. Also interestingly our study showed that the prevalence of pterygium increased with age until 69 years of age and then declined similar to another study ${ }^{26}$. In this study $51 \%$ subjects showed lid plugging and mucous threads. This mucus pattern brings changes in the 
ocular surface. Mucin reduces the surface tension of tears and increases the wettability of the hydrophobic lipoprotein epithelial surface ${ }^{23}$. This study was done to know the dry nature of the eyes having pterygium. Other studies have proved that pterygium excision improved tear osmolarity and tear film functions which were deteriorated again with the recurrence of pterygium ${ }^{26}$.

In this study when normal subjects were compared with pterygium patients, both tear film breakup time and Schirmer's test showed changed values. The tear film changes cause dellen formation leading to focal dryness.

The limitation of our study was that it was conducted in a single center. Further studies need to be done with larger sample size to improve the generalizability of the results.

\section{CONCLUSION}

There is a relation between tear film functions, ocular surface changes and pterygium. The function of Meibomian gland is derranged in pterygium patients which initiates dellen formation which leads to dryness. Pterygium disturbs tear functions causing dry eye like symptoms.

\section{REFERENCES}

1. Johnson RD, Pai VC, Hoft RH. Historical approaches to pterygium surgery, including bare sclera and adjunctive beta radiation techniques. In: Hovanesian JA, editor. Pterygium: Techniques and Technologies for Surgical Success. Thorofare, NJ: Slack Incorporated; 2012: 2012: 27-36.

2. Asokan R, Venkatasubbu RS, Velumuri L, Lingam V, George R. Prevalence and associated factors for pterygium and pinguecula in a South Indian population. Ophthalmic Physiol Opt. 2012; 32 (1): 39-44.

3. Cajucom-Uy H, Tong L, Wong TY, Tay WT, Saw SM. The prevalence of and risk factors for pterygium in an urban Malay population: the Singapore Malay Eye Study (SiMES). Br J Ophthalmol. 2010; 94: 977-81.

4. Wolff E. The mucocutaneous junction of the lid margin and distribution of the tear fluid. Trans Ophthalmol Soc UK, 1946; 66: 291Y308.

5. Yazici A, Sari ES, Sahin G, Kilic A, Cakmak H, Ayar $\mathrm{O}$, Ermis SS. Change in tear film characteristics in visual display terminal users. Eur J Ophthalmol. 2015 Mar-Apr; 25 (2): 85-9.

6. The definition and classification of dry eye disease: report of the Definition and Classification Subcommittee of the International Dry Eye Work Shop (2007). Ocul Surf. 2007 Apr; 5 (2): 75-92.
7. Lemp MA, Crews LA, Bron AJ, Foulks GN, Sullivan BD. Distribution of aqueous-deficient and evaporative dry eye in a clinic-based patient cohort: a retrospective study. Cornea, 2012; 31 (5): 472-478.

8. Paulsen AJ, Cruickshanks KJ, Fischer ME, Huang GH, Klein BEK, Klein R, Dalton DS. Dry Eye in the Beaver Dam Offspring Study: Prevalence, Risk Factors, and Health-Related Quality of Life. Am J Ophthalmol. 2014 Apr; 157 (4): 799-80.

9. McCarty CA, Bansal AK, Livingston PM, Stanislavsky YL, Taylor HR. The epidemiology of dry eye in Melbourne, Australia. Ophthalmology. 1998; 105: 11141119.

10. Lee AJ, Lee J, Saw SM, Gazzard G, Koh D, Widjaja D et al.. Prevalence and risk factors associated with dry eye symptoms: a population based study in Indonesia. Br J Ophthalmol. 2002; 86: 1347-1351.

11. Gonnermann J, Maier AK, Klein JP, Bertelmann E, Pleyer U, Klamann MK. Evaluation of ocular surface temperature in patients with pterygium. Curr Eye Res. 2014; 39: 359-64.

12. Chui JJY, Coroneo MT. Pterygium pathogenesis, actinic damage, and recurrence. In: Hovanesian JA, editor. Pterygium: Techniques and Technologies for Surgical Success. Thorofare, NJ: Slack Incorporated; 2012: 1-26.

13. Zhao L, You QS, Xu L, Ma K, Wang YX et al. Ten-year incidence and associations of pterygium in adult Chinese. The Beijing Eye Study. Invest Ophthalol Vis Sci (2013); 5: 1509-1514.

14. Viso E, Gude F, Rodríguez-Ares MT. Prevalence of pinguecula and pterygium in a general population in Spain. Eye (Lond) 2011; 25:350- 715.

15. Rahman A, Yahya K, Fasih U, Waqar-ul-Huda, Shaikh A. Comparison of Schirmer's test and tear film breakup time test to detect tear film abnormalities in patients with pterygium. J Pak Med Assoc. 2012; 62: 1214-6.

16. Ozsutcu M, Arslan B, Erdur SK, Gulkilik G, Kocabora SM, Muftuoglu O. Tear osmolarity and tear film parameters in patients with unilateral pterygium. Cornea, 2014; 33: 1174-8.

17. Sapkota K, Franco S, Sampaio P, Lira M. Goblet cell density association with tear function and ocular surface physiology. Cont Lens Anterior Eye, 2015; 38: 240-4.

18. Bekibele CO, Baiyeroju AM, Ajaiyeoba A, Akang EE, Ajayi BG. Case control study of dry eye and related ocular surface abnormalities in Ibadan, Nigeria. Int Ophthalmol 2010; 30: 7-13.

19. Roka N, Shrestha SP, Joshi ND. Assessment of tear secretion and tear film instability in cases with pterygium and normal subjects. Nepal J Ophthalmol. 2013; 5: 16-23.

20. Kampitak K, Leelawongtawun W. Precorneal tear film in pterygium eye. J Med Assoc Thai. 2014; 97: 536-9.

21. Li M, Zhang M, Lin $\mathrm{Y}$, Xiao $\mathrm{Q}$, Zhu X, Song S, et al. Tear function and goblet cell density after pterygium excision. Eye (Lond), 2007; 21: 224-228.

22. Türkyilmaz K, Oner V, Sevim MS, Kurt A, 
Sekeryapan B, Durmus M. Effect of pterygium surgery on tear osmolarity. J Ophthalmol. 2013; 2013: 863498.

23. Ye F, Zhou F, Xia Y, Zhu X, Yan Wu Y. Evaluation of meibomian gland and tear film changes in patients with pterygium Indian J Ophthalmol. 2017 Mar; 65 (3): 233237.

24. Zhong $H$, Cha $X$, Wei $T$, Lin $X$, Li $X$, Li J et al. Prevalence of and risk factors for pterygium in rural adult Chinese populations of the Bai nationality in Dali:

\section{Author's Affiliation}

Munir Baig

Department of Ophthalmology, Azad Jammu Kashmir Medical College Muzaffarabad

Dr. Rabeeya Munir

Oral Biology Islamic International Dental College Islamabad the Yunnan Minority Eye Study. Invest Ophthalmol Vis Sci, 2012; 53: 6617-6621.

25. Lu P, Chen X, Kang Y, Ke L, Wei X, Zhang W. Pterygium in Tibetans: a population-based study in China Clin Exp Ophthalmol. (2007); 35 (9): 828-833.

26. Kheirkhah A, Safi H, Molaei S, Nazari R, Behrouz MJ, Raju VK. Effects of pterygium surgery on front and back corneal astigmatism. Can J Ophthalmol. 2012; 47: 423-8.

\section{Author's Contribution}

Munir Baig

Study Design, Manuscript Writing, Data collection

Dr. Rabeeya Munir

Manuscript writing and critical analysis. 